\title{
Enfoque semiótico del Padrenuestro como base para una estructuración musical ${ }^{1}$
}

Jesús Arreguín Zozoaga 2

\section{Resumen}

Las religiones han sido siempre el paradigma por el que se ha interpretado y justificado el papel del Hombre y su relación con la divinidad. El fundamento de este trabajo, tiene esa inquietud de los seres humanos respecto a su origen y devenir en el tiempo, y está cristalizada en la Oración del Padrenuestro la cual plasma inquietudes comunes en muchas culturas y en términos generales engloba -con acepciones distintas- a gran parte de las religiones del mundo. Es innegable la magnificencia y el portento de la Divinidad que ha inspirado la creación de tanta belleza en la historia general del arte, conectando el espíritu del Hombre con el Creador. Se intenta reflejar esta premisa a partir del pensamiento filosófico impregnado en la Oración, con una perspectiva de interiorización psicológica independiente a cualquier credo religioso, devoción y retórica, a partir de sus implicaciones polisémicas para su aplicación en un discurso musical.

Palabras clave: Religión, tradición, filosófico, semiótico, música.

\begin{abstract}
Religions have always been the paradigm around which the role of Man and his relation with divinity has been interpreted and justified. The foundations of this work involve the concern human beings have, regarding their origin and development in time, and which is manifested in the Our Father prayer, deploying a number of worries common to varied cultures and in general terms involving - in different senses - a major part of the religions in the world. It is undeniable the magnificence and power of the divinity which has inspired the creation of so much beauty throughout the history of art, connecting the spirit of Man with the Creator. From the philosophic feeling prevailing in the prayer, this premise is intended to be reflected with a perspective of psychological familiarization beyond a particular religious belief, devotion, and rhetoric, coming from their polysemous implications for its application in a music discourse.
\end{abstract}

Keywords: Religion, tradition, philosophical, semiotic, music.

\footnotetext{
1 Este escrito forma parte de la tesis Padre Nostro para Soprano y Orquesta, "Una aproximación a las perspectivas del pensamiento, para la representación sonora de la Oración", del mismo autor.

2 Docente PTC del Instituto de Artes de la UAEH, con Licenciatura en Composición del Conservatorio Nacional de Música (México), Specializacione in Musica Contemporanea della Civica Scuola di Musica di Milano, -hoy IRMUS- (Italia). Tesista de la Maestría en Composición del Programa de Maestría y Doctorado en Música de la Facultad de Música -antes Escuela Nacional de Música- de la UNAM.
} 
Este trabajo plantea de manera parcial una perspectiva histórica de la humanidad a partir de la documentación bíblica y literatura en general hasta nuestros días. Una visión de cómo el Hombre necesita creer en algo más poderoso que él mismo -en las cosas de la vida que no están en su control- en quién 0 a qué ofrendarse en el futuro para no tener un juicio (remordimiento o crítica) tan severo al final de su existencia, independientemente de su tipo de vida y obra en ella. El objeto de estudio es El Padrenuestro, Oración que sirve de texto base en la composición de la obra (Padre Nostro para Soprano y Orquesta), y del que se desprende un enfoque hacia la veleidad humana que, eventualmente, puede justificar sus actos mediante la adhesión religiosa a través de las imprecisiones conceptuales y morales contenidas en algunos de sus preceptos y que desean con denuedo establecer un contacto desde su condición más pueril con la divinidad.

La reflexión y análisis sobre el sentido semántico de la Oración, incide en su representación musical -como un paralelismo- con el proceso de la celebración litúrgica de la misa en la Iglesia y la división formal de la pieza -no en el sentido de las obras antiguas que seguían la estructuración musical denominada precisamente como Misa, (Introito, Kyrie, Gloria, etc.)- sino con el ritual mismo, incidiendo particularmente en lo que se refiere a la Eucaristía, la cual representa simbólicamente la celebración por el pan y el vino, (la Iglesia relaciona a la Misa con el Sacrificio del Cuerpo y Sangre de Jesucristo en la Cruz). Esta tarea se divide parcialmente en dos aspectos concernientes a la parte histórico-filosófica y sus referentes semióticos, y a la parte lingüística a partir de algunos referentes de índole técnica que perfilan mediante la prosodia, y la semántica de la Oración, la musicalidad derivada del texto, aplicada a su posterior orquestación instrumental.

El análisis del texto se realiza porque es la base del trabajo de composición de la obra diseñada para una voz femenina que canta la Oración del Padrenuestro y una orquesta sinfónica que subraya con diversos colores instrumentales y orquestación sonora específica, las sutilezas y drama contenidos en ella, derivando esto de la prosodia inferida al discurso vocal (contenido semántico Representado), a manera de puente y decodificador entre el texto de la Oración (como símbolo Representante) y la resultante sonora global, Padre Nostro para Soprano y Orquesta (como Interpretante de la Oración empleada), y para que el análisis semiótico del texto evidencie los conceptos e interpretación que el autor quiere enfatizar, clarificar e inducir en la obra musical, para la comprensión de este trabajo fundamentado en un largo proceso de observación de la naturaleza humana y su desenvolvimiento en la sociedad a través de los años. 
Gestado en la observación de un entorno sociocultural común a muchos, este trabajo incide en la posibilidad de realizar una introspección en uno mismo a manera de ejercicio personal, para asumir una posición congruente con lo que se es y se hace (creemos o realizamos), en torno al arte, en relación a un código moral, a una conducta religiosa o práctica de cualquier inclinación con la que se comulgue, pues el espíritu que impulsa el presente trabajo -como ya se esbozó arriba- es obtener indicios que nos permitan percibir o recordar porqué somos de una manera en particular y no por una inercia generalizada o gastada por el tiempo y la retórica.

No obstante a la apertura que pueda arrojar el enfoque semiológico para un marco referencial amplio de la Oración, al esclarecer elementos técnicos, estéticos, históricos, etc., es probable que no mejore mucho la percepción de la música para quienes no tienen esa formación disciplinar pues existen articulaciones y convenciones sonoras muy sutiles que escapan con facilidad a la percepción, pues su asimilación en movimiento dista de lo cristalizado o inamovible. La música es la más abstracta de las disciplinas artísticas, subyace en la percepción, en las emociones, pertenece al ámbito de las sensaciones sin una significación concreta, aún el más conspicuo individuo puede no comprender el fenómeno musical si no mantuvo una relación directa con ella; como aduce Hernández (2012), "[...] siguen hablando de la gran importancia de la música para la sociedad sin saber cómo se podría estudiar esa importancia en el sonido musical mismo" (p. 43). Es necesario diferenciar que una cosa es la aportación de la semiótica a la comprensión de las cualidades emotivas, filosóficas, incluso subjetivas del pensamiento y creación humana, pero otra es la que se ubica en sus límites disciplinares donde sólo puede deducir o intuir y no afirmar, a menos que esté calificado en varios campos del conocimiento.

El producto que evidencia la capacidad de la creatividad humana y reviste una trascendencia prioritaria o fundamental en el proceso de la conformación histórica de las distintas culturas del Hombre, es un logro que debe analizarse para saber el alcance de su relevancia -trátese de la más natural e inmanente necesidad de sobrevivencia trámite la estructuración y adecuación del hábitat circundante, de alguna determinada Institución, o simplemente de una obra artística. Para el análisis de un determinado producto, como de su proceso de conformación es necesario tomar en cuenta muchos factores que aplican directamente al objeto de estudio y su contexto ya sean de índole disciplinar, histórico, técnico, etc.

Así, se tiene que para obtener una aproximación determinada al hipotético objeto de estudio, es menester ubicarse en el contexto, no obstante muchos análisis se realicen fuera o en ausencia de él, debido a una distancia temporal inasequible como el que se fundamenta en productos del pasado, dónde 
sólo el acervo bibliográfico u objeto arqueológico, nos permite acercarnos -detrás de un cristal- para observar y teorizar al respecto; tal fenómeno ocurre con las investigaciones de tipo antropológico, histórico y filosófico donde el enfoque semiótico es pertinente.

El proceso que en términos generales afecta la comprensión de un texto antiguo en nuestro contexto actual, es complicado en función de la interpretación que de la lengua original se debe hacer, pues existen varias circunstancias que afectan el resultado final. Esta tarea se divide parcialmente en dos aspectos concernientes a la parte histórico-filosófica y sus referentes semióticos, y a la parte lingüística a partir de algunos referentes de índole técnica para saber cómo se construye y articula el lenguaje, y que perfilan mediante la prosodia, la semántica del texto.

Todo esto, evidentemente influye en la musicalidad de la Oración, la cual es susceptible de orquestación instrumental, no obstante, esta parte del trabajo no está dentro de los parámetros de este medio.

Es sabido que la perspectiva de los acontecimientos dependen de la interpretación tanto individual (básicamente subjetiva), como de la social (el colectivo), puesto que todos los individuos son formantes de un nomos y esta condición de pertenencia que engloba, categoriza en un tipo particular de semiosfera; dada esta condición, un individuo no puede sustraerse fácilmente a su contexto y tradición pues de intentarlo el grupo cultural mismo se encarga de repelerlo del medio y se agudiza en comunidades pequeñas donde casi todos los pobladores de ella se conocen entre sí.

La interpretación en la conformación final de la Oración del Padrenuestro que nos ocupa, tuvo sus fuentes en diversas civilizaciones del mundo antiguo, como en la tradición de muchas culturas que no necesariamente desarrollaron una producción literaria de su propia evolución lingüística, como se concibe actualmente; civilizaciones donde la tradición oral fue fundamental para su posterior relación escrita, ya sea simbólica (encriptada), pictográfica o en una nomenclatura o sistema alfabético.

A través del análisis de la Oración y de rastros bibliográficos de su origen, se intenta llegar a validar el porqué de su pertinencia en la historia de la humanidad, si es posible saber a través de esta Oración quiénes somos y por qué, y si nos representa a todos, por lo tanto como dijera Durkheim, (1993), "Siempre que se intenta explicar un asunto humano tomado en un momento determinado del tiempo -ya se trate de una creencia religiosa, de una norma moral [...] es preciso comenzar por remontarse hasta su forma más primitiva y más simple [...]". (p. 15). 
La mayoría de las civilizaciones en el mundo han generado y estructurado su cosmogonía, en función de la percepción que tienen de aquel, de sus necesidades y del cómo se asumen en él. Cada una de las culturas ha representado a sus dioses a partir de sus parámetros estéticos, por ejemplo, la primera fase del imperio Romano (I-III d. C), tomó de referencia a importantes civilizaciones como la egipcia y griega -en el período grecorromano- y el cuerpo eclesial de la incipiente Iglesia retomó muchos de sus conceptos y elementos cosmogónicos y filosóficos para cimentarse, así como muchos siglos después, se apropió de los artísticos.

Los aspectos filosóficos fundamentales para la organización eclesial partieron de la concepción del universo teniendo como centro de este a la creación humana de Dios. El paradigma aristotélico respecto a la percepción y sustento de la entidad humana, fue una de las bases principales de la configuración de la teología cristiana aunado al dualismo emanado del pensamiento platónico, el cual preservaba de manera tangencial elementos del cristianismo primitivo que se debatía entre las diversas manifestaciones y fuerzas divinas heredadas del panteón griego. No obstante, ambas posturas embonaron perfectamente con la herencia dejada por Cristo en relación al retorno con el Padre de Todo, mediante la virtud conductual y espiritual del hombre. Esto, enriquecido en su conjunto, con lo establecido en el Antiguo y Nuevo Testamento en relación a que la sustancia del ser humano es inmanente al Creador por ser parte de su hálito de vida y haber sido hecho a su imagen y semejanza.

La idea teológica del Hombre esgrimida por la Iglesia está cifrada precisamente en esta relación de trascendencia y el kerigma -por el paso de Jesús entre los hombres- como procedimiento para conseguirlo. Esta promesa de vínculo directo con el Creador fue y continúa siendo sumamente atractiva incluso para la conversión espiritual -evidentemente bajo la premisa principal de cada individuo respecto a sus intereses en la vida- pues en efecto las facciones religiosas conocidas en el siglo III como cismáticas o heréticas sostenían algunos conceptos del cristianismo primitivo que convenían a sus seguidores para la consecución de sus intereses sin someterse a una ascesis profunda como la esgrimida -al menos en su inicio- por la ortodoxia. Indudablemente, la salvación y obtención del valor que la mayoría de los seres humanos suponen tener o desean, puede obtenerse bajo la perspectiva de la Iglesia trámite su percepción cristológica del Hombre.

Mediante el constante adoctrinamiento de la salvación por Cristo, se perfeccionó el objetivo ya no sólo como un tipo de filosofía sino como una entidad natural del Hombre, al grado de relacionarse de manera ontológica en una especie de mecánica biofísica de este, al tiempo que la apertura natural del pensamiento dualista -que resulta contraproducente al adoctrinamiento- se iba aboliendo. 
La perspectiva inicial que tuvo el proceso de integración a cargo de los hombres de Fe, para la unificación de un criterio religioso que acogiera a las distintas sedes religiosas diseminadas por todo el orbe y constituir lo que se conocería más tarde como "Iglesia" (a partir de la presencia y desaparición de Jesucristo), se esbozó fuertemente -según se desprende de las Cartas de Ignacio de Antioquía- a través de una estructuración basada en "tres componentes esenciales: el obispo, los presbíteros y los diáconos" (Grossi, V. 2013).

Los antecedentes y fuente principal para la organización de esta Institución fueron los testigos y entendidos de los hechos de la Pasión de Cristo mediante la tradición oral, situación fundamental para la conformación del primer Evangelio; evidentemente como la cultura griega gozaba aún de su prestigio Clásico, se presume la versión original de esta Oración en una versión dialectal del griego registrada en el Evangelio de Mateo (no obstante que la lengua materna de Cristo haya sido el arameo). En los Evangelios se hallan dos versiones del Padrenuestro: la de San Mateo que es la más larga y la que comúnmente se conoce y reza, y la de San Lucas, escritos de 20 a 30 años aproximadamente después de la muerte de Cristo. Esta Oración adjudicada a Cristo, es sólo la esencia de la que posteriormente se estableció.

Es pertinente recordar que la datación de la escritura de los Evangelios y algunas atribuciones de sus autores, son aproximaciones basadas en la tradición oral y deducción; este hecho ha derivado interpretaciones diversas por parte de historiadores, exégetas y teólogos. Observemos las siguientes consideraciones a propósito de ellos.

El primer Evangelio escrito en griego fue el de Marcos, hacia el 50 y 60 d. C., no fue testigo de los hechos narrados y se basó en los relatos de los discípulos, principalmente de Pedro de quién presumiblemente era secretario. El segundo Evangelio lo escribió el apóstol Mateo, testigo directo de los hechos que narra en arameo en su versión primitiva hacia los años 60-70 y se presume una ulterior redacción definitiva, a su vez por un discípulo de este. Referencias documentales argumentan que aproximadamente la mitad de su trabajo está basado en el de Marcos. El tercer Evangelio escrito hacia los 70-80 d. C., lo escribió Lucas en griego, quien asistía como médico al apóstol Pablo; y no fue testigo presencial de lo que escribió. Aproximadamente empleó tres cuartas partes de lo hecho por Marcos y una cuarta parte coincide con lo relatado por Mateo; fue el único de los evangelistas que no era judío. Finalmente el cuarto Evangelio escrito en griego hacia el año 95 por Juan, es el compendio de sus vivencias, siendo por lo tanto, el documento más detallado y preciso en cuanto a Cristo, precisamente por esta cercanía con él. (Magaña, A. 1986). 
Por otra parte y dos siglos más tarde, las ideas fueron aglutinándose paulatinamente y hubo también una cuidadosa manipulación de ellas para lograr una sistematización religiosa que sirviera de base para la constitución de un estado regulador que finalmente tendría el mismo resultado, esto es, la intermediación entre el Hombre y Dios. La concepción que se tenía del cristianismo hasta antes de que el emperador Constantino comenzara a organizar la institución eclesiástica, se circunscribía a la percepción del sentimiento religioso someramente constituido y que incluía a Roma y latitudes periféricas aún más allá de la península balcánica, en un período de inestabilidad por las diversas corrientes en pugna, pero con una paulatina pero constante condensación de seguidores de las enseñanzas de Cristo.

Esta situación llegó a tal punto que no sólo las distintas sectas (denominadas así por no ser aún legítimas), pugnaban por insertarse dentro de la legalidad de un culto afín al Imperio, sino que la organización eclesial también luchaba por legitimarse a sí misma dentro de un marco de referencia bien definido. A partir de la liberación de cultos impulsada por Constantino, comenzaron una serie de reformas en torno al tema del catolicismo tanto al interno del ámbito eclesiástico como hacia su representación institucional. Lo primordial fue organizar los términos que dieran coherencia al culto religioso y para esto hubo una serie de parámetros a discusión en la promulgación de actas, oficios, conferencias, etc., dentro del edicto de Constantino del 313. En reflexión de Grossi (2013), las asambleas que dirimían sobre el tópico argumentaban como base de legitimidad del culto, las Sagradas Escrituras, el hecho de que las iglesias organizadas en los límites territoriales u otros países como África, por ejemplo, hubieran sido fundadas por apóstoles o seguidores de ellos, así como su dirigencia a cargo de obispos que eran prácticamente como en el antiguo Egipto, representantes de la divinidad o de Cristo, eran también elementos que caracterizaban y legitimaban la pertinencia de la actividad religiosa de dichas iglesias, pues implicaba que los fieles serían también puros y castos como sus dirigentes. La adjetivación de iglesia ortodoxa y cismática o herética, estaba en función de estas características, y fue fundamentalmente este el tema de discusión constante; fue así que muchos escritos que no eran afines o coherentes con a esa “legitimación” acariciada quedaron fuera, siglos más tarde, serían conocidos como apócrifos.

Algunos representantes del culto no centralizado defendían sus posturas mediante diversos ejemplos de interpretación exegética de documentos sagrados quienes a su vez eran interpelados por el consejo y representantes de la Iglesia que se presumía como la verdadera o "Imperial"; en este sentido, comenzaron a gestarse primeramente los términos en los que tenía que ser concebida esta Iglesia para estructurarse posteriormente como "Iglesia católica". 
Aunque la Oración del Padrenuestro ya está esbozada en los Evangelios de Mateo y Lucas, su antecedente práctico -para no reiterar e incurrir en otros términos- los estableció de forma contundente Constantino.

...Como una de las reminiscencias que trajo consigo Constantino de la familia de Cloro se presenta el monoteísmo tolerante, al que se había entregado éste. El primer testimonio religioso vivo nos lo ofrece la visita de Constantino al templo de Apolo en Autun (308), [...] El mismo Cloro concebía al ser supremo como un dios solar. [...] Las letras X y P entrelazadas, que constituyen

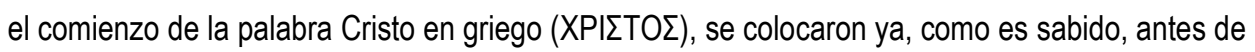
la guerra en los escudos de los soldados. Al mismo tiempo, o quizá más tarde, se coloca en un gran estandarte el mismo monograma, rodeado de oro y pedrería, y este lábaro fue objeto de un culto especial e inspiraba a los guerreros la máxima confianza en la victoria. [...] Cristo podía pasar como un dios junto a los demás, y sus creyentes como súbditos junto a los creyentes en los dioses paganos. No negamos la posibilidad que en Constantino surgiera una cierta superstición a favor de Cristo, en tal forma que acaso estableciera una confusa combinación entre ese nombre y su dios solar; pero lo que le importaba era el éxito. [...] El emperador juró al obispo que no era cuento sino que vio de verdad aquella cruz en el cielo con la inscripción "con este signo vencerás" y que Cristo se le apareció en sueños, etc. [...] A este género pertenecen el día de domingo común y el Pater Noster común. "Instruyó a todos los ejércitos a honrar el día del Señor, que también es llamado día de la Luz y del Sol... también los paganos tenían que marchar en domingo al campo y elevar las manos pronunciando una oración, aprendida de memoria, en honor de Dios, autor de todas las victorias: A ti sólo te reconocemos como Dios y como Rey, a Ti sólo te imploramos como socorro nuestro. De Ti hemos recibido la victoria, gracias a Ti hemos vencido a los enemigos. A Ti te agradecemos el bien que hemos recibido y de Ti esperamos el bien que ha de venir. A Ti te imploramos y rogamos para que nos conserves incólumes y victoriosos, por muchos años, a nuestro emperador Constantino y a sus hijos, amantes de Dios".

(Burckhardt, J. 1945, pp.331-338)

Este tipo de plegarias contextualizadas en el ámbito espiritual y religioso se encuentran desde antes del cristianismo, en gran parte de la influencia grecorromana y permanecen aún en la cultura hebrea y judía.

Las referencias y comparaciones en torno a la interpretación de los textos bíblicos, han ido cambiado de manera sutil y paulatinamente las posturas de los estudiosos a lo largo de los años en función de nuevos criterios y perspectivas filosóficas derivadas de sus propias culturas y también de los avances

\footnotetext{
${ }^{3}$ Nota del autor. Euseb. Vita Const. IV, 18-20. Según el comienzo del cap. 19 se podía creer que la oración se refería sólo a los paganos; sin embargo, después se habla otra vez de "todos los soldados". Parece que la oración estaba adaptada para servir a las dos religiones. - La prohibición del trabajo manual y de las sesiones de los tribunales los domingos procede del año 321; cf. Manso, ob cit., p. 95 N. Los paganos no le hicieron mucho caso. Cf. Euseb. I, cap. IV, 23. - Solían celebrar los Dies Saturni, cf. Tertullian., Apolog. 16.
} 
científicos como los de Leeuwenhoek (1600 ca.) a propósito de los protozoarios por ejemplo, o el caso de Linneo (1700 ca.), también relacionado con estos infusorios que se abordará a continuación, así como hallazgos documentales como los denominados Evangelios apócrifos (1945 en Nag Hammadi, Egipto), y los llamados rollos del Mar Muerto (1947 en Qumram, Palestina), que arrojaron respectivamente, una nueva luz sobre la relación histórica de la vida de Jesucristo y de la religión judía de entonces.

No es necesario ahondar, pero si recordar que la historia en su proceso y análisis ha sido cambiada así como sus componentes internos y personajes; las interpretaciones son muchas y las manipulaciones -en un sentido ascético del término- han metamorfoseado o cambiado los conceptos e interpretaciones iniciales. De manera rápida se han visualizado los cambios que ha tenido el Hombre desde sus conceptos iniciales hasta los contemporáneos, por lo tanto, en relación al tema de este trabajo, también se pueden deducir, las múltiples implicaciones e interpretaciones que ha tenido la mencionada Oración del Padrenuestro. La creación del universo por el Todopoderoso y la veracidad de su obra descrita como tal en la Biblia, no contempla muchos aspectos de la naturaleza y de los procesos de la misma, por lo que en épocas distintas surgieron problemas de interpretación, muchos de los cuales fueron evidenciados por grandes pensadores mediante avances en el terreno de las ciencias a pesar de los esfuerzos denodados de la Iglesia por mantener vigente el dogma.

De varias partes de Europa se habían enviado noticias con toda clase de detalles a la Real Academia de Ciencias, referentes a grandes cantidades de agua que se habian convertido en sangre. Eclesiásticos bien intencionados vieron en esto una indicación de la ira de Dios, [...] Un milagro de esta clase ocurrió en Suecia, y Linneo estudió el fenómeno cuidadosamente, llegando a la conclusión de que el enrojecimiento del agua era debido a la presencia de grandes masas de infusorios. La noticia de tal explicación pronto llegó a oídos del obispo y éste tomó partido contra Linneo, denunciando su descubrimiento científico como "un abismo satánico" [...] En vista de esta furibunda embestida, Linneo emprendió la retirada. (Dickson, A. 1972, pp. 83-84)

La Iglesia definió el origen del Hombre mediante la concepción de lo que se denomina alma y que cristalizó en Santo Tomás, caracterizando no de manera independiente a la materia sino en una especie de binomio que cohesionaba la materialidad corpórea con la sustancia espiritual como característica legítima del mismo Creador, lo que implicaba la simultaneidad de esa jerarquía dual al momento de nacer.

Finalmente, con base en lo anterior, las posibilidades de interpretación del origen del Hombre no circunscritas al dogma o a partir de posturas no religiosas como las basadas en hipótesis científicas 0 
naturalistas (evolucionistas), descartan -en el mundo contemporáneo- la posibilidad de que en un proceso de evolución y desarrollo de sus distintas fases, se verifique esa relación de Cuerpo-Alma en ese digamos, pre homínido, debido a que no se le puede considerar como una creación divina.

Por lo tanto el binomio aludido sólo es posible hasta que nos encontramos con el Hombre, tal y como lo conocemos, lo cual plantea otra discusión nada fácil, respecto al momento en que se considera que un ser humano en gestación uterina ya tiene el hálito de vida, y por consiguiente, si es o no divino.

La historia del Hombre evidencia como el ser humano ha construido todo la tecnología hasta lo que en la actualidad somos incluyendo el desarrollo filosófico y artístico independientes al dogma. Se tiene la percepción de que el destino del Hombre ya está trazado (está escrito), como la de que su destino está en sus propias manos, etc. La naturaleza humana no sólo es inmanente al ser, el contexto y el transcurso de la vida misma lo perfilan profundamente y de manera continua, por lo tanto, distintas vertientes confluyen en la conducta de los seres humanos, y los valores que le dan su calidad dependerán en efecto, de él mismo.

En mi opinión, creo que lo que en realidad pasa es que se sigue en la política de las 'adaptaciones ad hoc' y de la tendencia al 'incompromiso hermenéutico' [escrito así por el autor], ya que se sabe que lo que en el fondo habría que hacer es proceder a una reconstrucción global de la hermenéutica del kerigma cristiano en el mundo moderno, y esto se ve como una aventura que crea una angustia invencible para algunos, hasta el momento, que lleva a no remover demasiado las cosas y dejarlas con 'prudencia' como están. Esto produce una cierta sensación de desconcierto, ya que nadie sabe con una cierta seguridad lo que se debe hacer para identificarse con el 'sentir de la iglesia". (Monserrat, J. 2011).

Por otra parte, haciendo una reflexión general sobre lo que conlleva la traducción de poesía de un idioma a otro, de un texto de un sistema alfabético a otro, o más aún, de un texto antiguo con ambas características; podemos imaginar el amplio espectro de posibilidades, acepciones y suposiciones subjetivas que se generan, a partir de aspectos concernientes a la parte histórico-filosófica y a los referentes semióticos del texto a tratar. Es evidente que dichos resultados traen consigo una serie de componentes adheridos, derivados del complejo viaje de interpretación lingüística y su traducción desde su origen (contextual más que etimológico), hasta nuestra realidad; estos se pueden inferir como efectos de pérdida de referente original del objeto de estudio, inmanente a la traducción que troca la interpretación del texto. 
Se hace referencia breve de los aspectos básicos que deben tenerse en consideración para realizar la traducción de textos como el que nos ocupa.

En primer lugar debe realizarse una adecuación (transliteración) de la lengua original al alfabeto latino, que es el que nos pertenece culturalmente.

En segundo lugar, ya latinizado el texto, debe realizarse la traducción al idioma o lengua de que se trate, siendo en este caso el arameo y griego.

El tercer paso es la traducción al idioma deseado, que en este caso es el latín por razones del tema que se está abordando.

Un cuarto procedimiento (por razones culturales), es la traducción del idioma italiano al español.

Como ilustración a este proceso se presentan las siguientes tablas a partir del supuesto rezo en la presunta lengua de Cristo (Arameo de Galilea).Transliteración del arameo.4

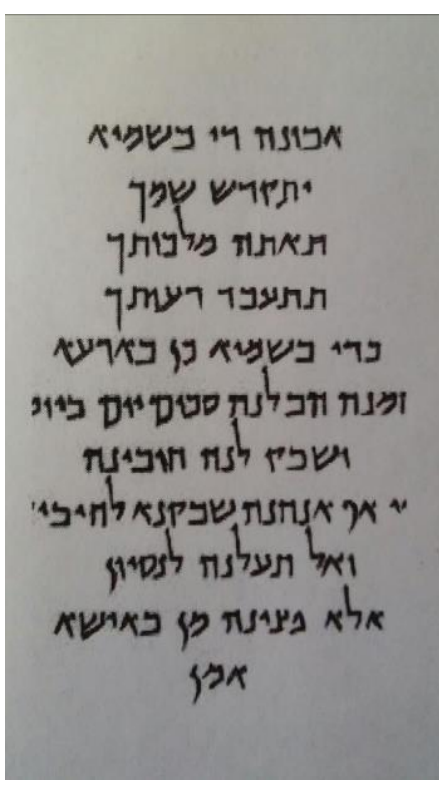

\begin{tabular}{|l|l|}
\hline Transliteración (latinizada) & Español \\
\hline Abun dabashmaya & Padre nuestro en el cielo, \\
\hline nethkadash shamak & Santo es tu nombre. \\
\hline tetha malkuthak & Tu reino viene, \\
\hline newe tzevyanak: aykan dabashmaya & $\begin{array}{l}\text { Tu voluntad se hace, tanto en el cielo como } \\
\text { en la tierra. }\end{array}$ \\
\hline af bara hav lan lakma dsunkanan & Danos hoy el pan que necesitamos \\
\hline yamana washbuk lan, kavine aykana daf & $\begin{array}{l}\text { Perdona nuestras ofensas, como ya hemos } \\
\text { perdonado a quienes nos ofenden }\end{array}$ \\
\hline hanan shabukan lhayavine ulow talahn lanesyana & No nos lleves a la tentación \\
\hline ela fatsan men bisha & Y líbranos del error. \\
\hline & \\
\hline Aa-meen & Amen. \\
\hline
\end{tabular}

A continuación, se pueden observar una serie de diferencias en la articulación del lenguaje, en lenguas emparentadas. ${ }^{5}$

\footnotetext{
${ }^{4}$ Consulta genérica del internet cuyo valor estriba en la guía -ejemplo- que proporciona para la reflexión de lo que se comenta, más que en la exactitud de su significado (imagen-texto), pues es por todos conocida la diferencia de interpretación de palabras y conceptos entre una demarcación, ciudad o país que comparten el mismo idioma.

${ }^{5}$ Consulta genérica del internet. Ibídem.
} 


\begin{tabular}{|l|l|l|}
\hline Arameo de Cristo & Arameo hebreo & Hebreo católico (actual) \\
\hline Avvon Abun dabashmaya & Avvon d-bish-maiya & Avinu shebashayim, \\
\hline & & \\
\hline nethkadash shamak & nith-qaddash shim-mukh & yitkadash sh'meka, \\
\hline tetha malkuthak & Tih-teh mal-chootukh & tavo malkhuteka \\
\hline newe tzevyanak: aykan dabashmaya & Nih-weh giw-yabukh: Ei-chana d'bish-maiya: ap bár-ah & Yeyasse r'tsonkha k'mo bashamayim keyn ba'rets. \\
\hline af bara hav lan lakma dsunkanan & Haw lan lakh-ma d'soonqa-anan yoo-mana & Et lekhem khukeynu teyn lanu \\
\hline yamana washbuk lan, kavine aykana daf & $\begin{array}{l}\text { O'shwooq lan kho-bein: Ei-chana d'ap kh'nan shwiq-qan } \\
\text { I'khaya-ween }\end{array}$ & $\begin{array}{l}\text { A hayom, uslakh lanu et khovoteynu kaasher } \\
\text { salahknu gam anakhnu lehkayaveynu }\end{array}$ \\
\hline $\begin{array}{l}\text { Hanan shabukan lhayavine ulow talahn } \\
\text { lanesyana }\end{array}$ & Oo'la te-ellan l'niss-yoona: & veal-t'vyeynu liydey misayon ki \\
\hline ela fatsan men bisha & & \\
\hline Aa-meen & il-la pac-shan min beesha & Av im-haltseynu min \\
\hline
\end{tabular}

Tomando en cuenta que todo lenguaje está en flujo continuo y naturalmente se va adecuando a las circunstancias, en este ejemplo se evdencian mutaciones en lenguas de raíces semiticas.

\begin{tabular}{|c|c|c|c|}
\hline & Arameo Hebreo & Árabe & Siríaco \\
\hline Padrenuestro & Abwoon Avinu & Aba-na & Abwoon \\
\hline & (אבינו) & 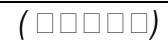 & $(a-r)$ \\
\hline
\end{tabular}

A partir de esto, se observa que en la búsqueda por la traducción "real" de la Oración, se pierde claridad en su objetivo, esto es, su interpretación. La tarea del especialista en teología, lenguas, e historia de las religiones se hace imprescindible, no obstante lo único en lo que podrán estar de acuerdo es en su esencia general. 6

En función de las distintas interpretaciones y variaciones que presentan -inflexiones dialectales y significados- las lenguas semitas (contexto de la Oración), así como de las regiones y raíces culturales, que comparten sus hablantes, se toma ahora (por su relevancia histórica), a la cultura griega como otra fuente y parámetro de la Oración.

${ }^{6}$ El concepto sobre la divinidad es arquetípico y universal, pasando por las civilizaciones mesopotámica, babilónica, egipcia, etc., hasta la época actual en el judaísmo y el islam donde prevalecen celebraciones -referidas en la Torá- como el Sabbat, emparentadas a los antiguos preceptos filosóficos y ceremoniales religiosos del cristianismo -como la Oración dominical del Padrenuestro- delineada en la Biblia. 
Recordemos que el griego fungió como lengua culta incluso en los tiempos de Cristo y fue empleado también por los evangelistas.

\begin{tabular}{|c|c|c|}
\hline Griego & Transliteración (latinizada) & Latín \\
\hline 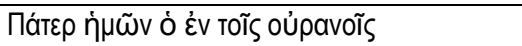 & Páter hemón, ho en tois ouranís & Pater noster, qui es in caelis \\
\hline 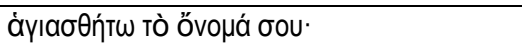 & hagiastheto to ónomá sou. & Sanctificetur nomen tuum. \\
\hline 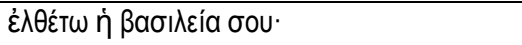 & eltheto he basileía sou. & Adveniat regnum tuum. \\
\hline 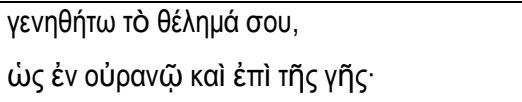 & $\begin{array}{l}\text { genitheto to thélemá sou, } \\
\text { hos en uranói, kai epí tes ges. }\end{array}$ & $\begin{array}{l}\text { Fiat voluntas tua, } \\
\text { sicut in caelo, et in terra. }\end{array}$ \\
\hline 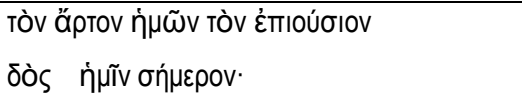 & $\begin{array}{l}\text { ton arton hemón ton epiousion } \\
\text { dos hemín sémeron. }\end{array}$ & $\begin{array}{l}\text { Panem nostrum quotidianum } \\
\text { da nobis hodie }\end{array}$ \\
\hline 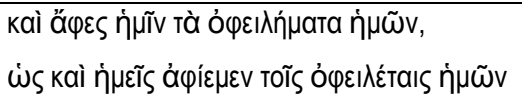 & $\begin{array}{l}\text { kai aphes hemín ta opheilémata hemón, } \\
\text { hos kai hemeís aphiemen tois opheiletais hemón }\end{array}$ & $\begin{array}{l}\text { Et dimitte nobis debita nostra, } \\
\text { sicut et nos dimittimus debitoribus nostris }\end{array}$ \\
\hline 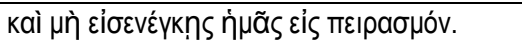 & kai me eisenenkeis hemás eis peirasmón. & Et ne nos inducas in tentationem \\
\hline 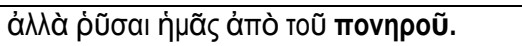 & allá rhusai hemás apó tou poneroú. & Sed libera nos a malo. \\
\hline maliciosamente & & conducir \\
\hline áuńv. & Amín. & Amen. \\
\hline
\end{tabular}

\section{Es necesario observar cómo se modifica la Oración en italiano a partir de la versión en latín y la traducida posteriormente al español.}

\begin{tabular}{|l|l|l|}
\hline Latín & Italiano & Español \\
\hline Pater noster, qui es in caelis & Padre Nostro, che sei nei cieli, & Padre nuestro, que estás en los cielos \\
\hline Sanctificetur nomen tuum & sia santificato il Tuo nome & Santificado sea tu nombre; \\
\hline Adveniat regnum tuum & venga il tuo regno, & Venga tu reino \\
\hline $\begin{array}{l}\text { Fiat voluntas tua, } \\
\text { sicut in caelo, et in terra }\end{array}$ & $\begin{array}{l}\text { sia fatta la Tua volontá, } \\
\text { come in cielo cosí in terra. }\end{array}$ & $\begin{array}{l}\text { Hágase tu voluntad, } \\
\text { como en el cielo, así en la tierra, }\end{array}$ \\
\hline Panem nostrum quotidianum & Dacci oggi il nostro pane quotidiano, & Danos hoy nuestro pan de cada día. \\
\hline $\begin{array}{l}\text { Et dimitte nobis debita nostra, } \\
\text { sicut et nos dimittimus debitoribus nostris }\end{array}$ & come noi li rimettiamo ai nostri debitori & $\begin{array}{l}\text { Perdona nuestras deudas, } \\
\text { como nosotros las perdonamos a nuestros deudores }\end{array}$ \\
\hline Et ne nos inducas in tentationem & E non ci indurre in tentazione & Y no nos induzcas en la tentación \\
\hline Sed libera nos a malo. & Ma liberaci dal male & sino líbranos del mal. \\
\hline \multicolumn{1}{c|}{ mal malo } & Anducir & Amen \\
\hline Amen. & & \\
\hline
\end{tabular}


Se puede apreciar en el ejemplo que a partir de las traducciones al italiano y español se aprecian cambios sintácticos a partir de la segunda línea así como ciertas declinaciones que se dan en relación a la versión oficial de la Oración, consignada en los catecismos cristianos.

Cambios en la traducción que seguramente pueden ser por razones gramaticales 0 de índole poética y métrica, sin embargo, son relevantes por el cambio de concepto que puede generarse sobre todo a partir de las tres últimas peticiones. Si esto es evidente en la actualidad con lenguas "vivas" es fácil suponer las múltiples concepciones desde la propuesta original.

El texto en italiano tiene una perspectiva semiótica más directa con el latín que el traducido al español, en relación a la teoría de los signos y aquello a lo que refieren (sus designata, o denotata). Esta teoría contiene la teoría de la verdad ( $v$., definición semántica), y la teoría de la deducción lógica. ${ }^{7}$ La versión italiana de la Oración que se expone pertenece al misal de la Iglesia católica italiana. La versión en español que se refiere a continuación está concebida en tres partes; Invocación, siete peticiones y doxología, 8 las cuales, se aplican a la estructuración de la obra musical.

Invocación: $\quad$ Padre nuestro, que estás en los cielos.

\section{Peticiones:}

1. Santificado sea tu nombre;

2. Venga a nosotros tu reino;

3. Hágase tu voluntad en la tierra, como en el cielo;

4. Danos hoy nuestro pan de cada día;

5. Perdona nuestras ofensas como también nosotros perdonamos a los que nos ofenden; 6. No nos dejes caer en tentación;

7. Y líbranos del mal. (Amén)

Doxología:

Tuyo es el reino, el poder y la gloria por siempre, Señor. Amén

La doxología no es parte original de la concepción de la Oración, es una reflexión posterior de ella. ${ }^{9}$

\footnotetext{
7 Diccionario de filosofía. Runes. p. 340

${ }^{8}$ Apartado 2855 del Catecismo de la Iglesia Católica.

9 La doxología es un agregado surgido según el teólogo luterano Joachim Jeremias (1900-1979), entre los siglos II y III d. C., pues era inaceptable que la oración terminara con la palabra tentación, y por lo tanto la Iglesia primitiva añadió para el uso litúrgico esta doxología, basándose probablemente en el texto de 1 Crónicas:29:11-13
} 
En relación al análisis del texto y su relación con la música -a partir de referentes directos del discurso con el desarrollo del proceso musical- mediante equivalencias simbólicas entre planos sonoros, texturas, dinámicas, etc., se observará aquí lo referente al aspecto de la palabra y generalidades que permiten que de ella se sustraiga parte de su esencia tanto semiótica como musical.

Uno de los parámetros lingüísticos aplicables al texto parte de la emisión de la palabra misma y su calidad expresiva a través de su prosodia; es decir, de la pronunciación correcta de las palabras en cualquier lenguaje, dotadas de una determinada musicalidad que le confiere el equilibrio de su articulación. Los orígenes sobre la Prosodia (hacia el canto), se remiten a los tiempos de la República de Platón, en donde diserta sobre el ritmo y modulación (musical) de parte de quien narra una historia; asociando la música con el habla en cuanto a las variaciones en tono e inflexiones de la voz. "Asumía el filósofo, además, que los diferentes modos musicales o prosóidíai (PROS\%DIAI) imitaban las diferentes maneras de hablar". (Mora, E. \& Asuaje, R. 2012).

En la cotidianidad, la manera en cómo se articula el lenguaje, esto es, la acentuación, el ritmo y la entonación son las cualidades que proveen de musicalidad al habla y permite identificar desde la sexualidad del interlocutor hasta su contexto socio cultural, por ejemplo; toda esta musicalidad provista a las palabras y las cualidades específicas de un tipo particular de voz, son en gran parte responsables de la comprensión del significado o mensaje que se transmite. Es en este ámbito donde la musicalidad impresa a la palabra -con todos sus elementos dispuestos de manera específica en cierto momento o tiempo, y de manera conjunta con una determinada instrumentación y campo sonoro- imprime una particular percepción semántica del texto y de las intenciones del autor. Según Méndez, A. (2012), Rousseau pensó que "toda música extrae su carácter principal de la lengua que es propia de su contexto social, en particular de su contexto nacional. Sería la prosodia de la lengua la principal responsable del carácter musical propio de una sociedad". Así, el contexto general permea las individualidades contenidas en él, y las condiciona subordinándolas a esa manera de percibir, en este caso, el fenómeno musical y derivar en su desarrollo una estética cultural. Por lo tanto, el comportamiento de la música está influido por una especie de proceso orgánico que involucra las percepciones psicológicas, sociológicas e ideológicas de una determinada cultura.

Esto es de gran importancia toda vez que por un tipo de retórica tanto estética como histórica, suele suceder que las sutilezas pueden ser soslayadas en aras de una ejecución instrumental per se. Es necesario que el músico tenga la humildad y aplicación de su experiencia musical, histórica y técnica en el 
ámbito de la ejecución como si estuviera interpretando la obra de alguno de los grandes compositores de todos los tiempos en su presencia, para proporcionar (al menos de manera parcial), una "elocuente" interpretación de ella al público.

En la interpretación musical, la experiencia fenoménica es, al mismo tiempo, interpretante y objeto, en la medida en que el intérprete vive el objeto y esta vivencia, a la vez, le proporciona los insumos para significaciones más racionalizadas que permitan la generación de nuevos signos de la obra musical. El intérprete musical instrumentista, por lo general, empieza a construir el objeto musical de su interpretación a partir de su experiencia y no de su abstracción. (Vinasco, J. 2012).

Una de las situaciones que ayuda al público a comprender aunque sólo en aspectos referenciales básicos son los programas de mano o sinopsis de la manifestación artística a la que acude, ya sea una obra musical, cine, obra de teatro o danza, etc., en este caso es importantísimo también que la redacción y conceptos vertidos ahí, tengan una claridad basada en la sencillez, para la mejor comprensión de un público general, quizá no avezado en el tema.

\footnotetext{
Las palabras pueden transmitir significados distintos de los expresados conscientemente por los hablantes o los escritores porque los oyentes o lectores aportan sus propias perspectivas a los mensajes que reciben. El hecho que el lenguaje no siempre sea fiable para generar unos significados precisos en la mente de otra persona es un reflejo de su fuerza como medio para crear nuevas comprensiones. (Galicia, M. \& Orozco, G. 2013).
}

La acentuación correcta de una palabra y su contextualización en el enunciado mediante los signos de puntuación proveen la cadencia natural del contenido semántico en cuestión, como también la manipulación al cambiar de lugar estas incidencias prosódicas con las cuales se desvirtúa el sentido original de un determinado texto o bien se troca a propósito el sentido del mismo. En este particular se tiene que circunscribir tal sentido a una voluntad ex profeso de incidir en un cambio de percepción natural del enunciado que se aborde, tanto literario, como musical por ejemplo. Otros códigos de representación semiótica que inciden en la interpretación que la gente tiene de las cosas más allá del significado aparentemente real de la palabra, son los generados por la comunicación no verbal. En la interpretación musical además de la gestualidad natural en la ejecución o por su naturaleza expresiva, puede incidir la 
proxémica $^{10}$ como se da en las relaciones sociales; ésta es aplicable a varias disciplinas, como sucede en el arte dramático al crear una emoción particular en función a la proximidad entre actores y público -en un recinto pequeño- al grado de percibir una fuerza expresiva mayor debido a su cercanía. Así, aunque en una representación musical la distancia pueda ser mayor a 4 metros, entre emisor y receptor, la elocuencia del mensaje será enriquecida incluso por la teatralidad generada por el intérprete. ${ }^{11}$ Aún en lejanía, la teatralidad que induce una gestualidad de intimidad o acercamiento al interlocutor (público) mediante el lenguaje corporal, da a este otra percepción que si sólo se supeditara al discurso ya sea hablado 0 cantado; en el entendido de que la proxémica es "el estudio de la forma en que las personas utilizan el espacio, bien sea personal y/o social para comunicarse". (Vallejo, G. 2011).

En la obra Padre Nostro para Soprano y Orquesta existe un episodio que alude a la Eucaristía al consagrar el vino y el pan -suenan las campanillas en la celebración litúrgica e infieren el arrodillamiento y anuencia- con un gesto musical representado por cuatro golpes rápidos, articulados con el glockenspiel y el vibráfono, y como yuxtaposición simbólica dos golpes simultáneos más fuertes, uno con la frusta o látigo 12 y otro con una cadena sobre un cubo de lámina de metal que sugieren otra lectura e interpretación semántica (del gesto y sus materiales físicos de articulación), no sólo de índole musical sino fuera del contexto de la tradición religiosa. Una connotación particular que también realiza en sí misma, un relato.

\begin{abstract}
Claro que nunca se puede hablar propiamente de "voz", en el sentido de que la música no habla, pero sí es admisible que comente o explique desde fuera lo que ocurre en la historia, es decir que participe en la "instancia relatora", contribuyendo a ordenar el relato. [...] No atribuiremos esa función de la música específicamente a la orquesta, aunque en muchas ocasiones asuma el protagonismo hasta el punto de que pueda haberse dicho que era un personaje más.
\end{abstract}

(Martín, M. 2014).

Si la participación del percusionista con cadena y cubo de metal ocupa visualmente un lugar protagonista como símbolo semiótico del discurso musical- la percepción cambia radicalmente a si permanece diseminado entre los demás instrumentistas como habitualmente sucede con el set de percusiones.

\footnotetext{
10 Distancia de interacción en la comunicación social como un aporte de expresividad y elocuencia al discurso, en función del espacio en el que se interactúe, caracterizada por el antropólogo norteamericano Edward Hall (1959-1966), en cuatro jerarquizaciones espaciales: intima de 15 a $45 \mathrm{~cm}$., personal de 46 a $120 \mathrm{~cm}$., social de 120 a $360 \mathrm{~cm}$., y pública de más de $360 \mathrm{~cm}$.

${ }^{11}$ Existen caricaturas que hacen referencia al pianista y compositor Franz Liszt, cuando realizaba sus recitales privados (sólo para los íntimos), evidenciando la impresión que causaba en las jóvenes al activar sus fluidos, no sólo por el desplante escénico sino por su proximidad con el gran artista.

12 Instrumento de percusión constituido de dos pequeñas tablas rectangulares de formato pequeño que al golpearse entre sí producen un sonido agudo y resonante, por coincidir perfectamente en su perpendicularidad al chocar.
} 
Imaginemos la fuerza connotativa que resultaría de esto si fuera puesto en relieve con una iluminación protagonista. ${ }^{13}$

Como argumenta Ussa, M. C., (2013), La conciencia, en la actitud gestual favorece la adecuada expresividad y, en consecuencia, la coherencia del discurso. [...] El gesto constituye parte esencial del discurso y, a su vez, se convierte en espacio donde el comportamiento cognitivo de los interlocutores es el reflejo de sus estados de conciencia.

Huelga decir, que el cúmulo de experiencias de los individuos, potencia la interacción con la experiencia percibida en función de la cantidad de relaciones semánticas que pueda interpretar ya sea a partir de su almacenamiento en la memoria, como de los conocimientos disciplinares de su competencia, 0 simplemente de su percepción y capacidad de integración de estos para desarrollar un nuevo conocimiento o enfoque. Recordemos que la activación de un elemento matérico o conceptual con un significado per se, cambiará en función del contexto en el que se aplique, pues la percepción de esos elementos puestos en juego, adquieren un relato o semántica particular bajo las circunstancias específicas en que las percibimos. El resultado o peso simbólico de esto, impacta de manera disímbola en quienes tienen buena intuición, competencia disciplinar específica, y en quienes adolecen de ella; así, no obstante el ámbito del conocimiento humano en el que se enfoque esta circunstancia, se pretende "un análisis de la significación como concurrencia de tres instancias: representante (o signo), representado (de lo que el signo da cuenta); e intérprete genérico, un muestrario representativo portador de los hábitos interpretativos de la comunidad a la cual pertenece". (Torres, E. 2012).

Ejemplo de esto puede ser el acto de persignarse ante una representación icónica sagrada, o como al acto de la genuflexión ${ }^{14}$ cuando alguien cruza frente a esa imagen, así como entre la oración del individuo y esta. Para el individuo que interactúa solamente de manera social sin tener claro cuáles son los códigos y normas basta la repetición del gesto, porque así es la "tradición", pero otros siguen el protocolo. Recordemos que la memoria es un proceso neurológico que realiza cada ser humano y está condicionado por el contexto y por el detonador que la activa, desde el acto voluntario de recordar hasta el sinestésico, por lo tanto puede tener variantes de aproximación a esta desde las personales hasta las colectivas.

\footnotetext{
${ }^{13}$ En el final de la obra Partiels de Gérard Grisey, un percusionista debe recibir iluminación paulatina en escena, creando la expectativa sonora a partir del choque de los platos que no alcanza a articular.

${ }^{14}$ Actitud de respeto o solicitud-permiso mediante una leve deferencia corporal o cadencia con tendencia al arrodillamiento.
} 
Se distinguen tres momentos en el proceso de memoria: adquisición, retención y recuperación (es decir, generar mecanismos para codificar la información, registrarla y luego recuperarla). Los distintos tipos de memoria (por su naturaleza, duración, contenido, forma de procesamiento) muestran la indisoluble conexión entre lo individual y lo social y la manera en que los procesos cognitivos se encuentran asociados a procesos sociales. (Ricaurte, P. 2014).

Ser congruente, con mente sana en cuerpo sano, y receptáculo de mejor y más sustanciosa información que enriquezca nuestra percepción del contexto en el que vivimos, implica nutrientes idóneos para ello, pues las impresiones que obtenemos de ese "mundo" circundante están filtradas por nuestra interpretación -que potencialmente- será vertida a nuestros interlocutores con una percepción que refuerce la experiencia o impresión sensorial y cognitiva, o la debilite mediante un tamiz, filtro o cualquier otro parámetro subjetivo.

Al retomar -con estos rastros- la interpretación del Padrenuestro y su empleo milenario, el cedazo de distintas culturas, la orfandad del ser humano que busca cobijo y su implicación moral condicionante, resulta que su alcance para el Hombre común -ante la imposibilidad del conocimiento hermenéutico y filológico profundo de los especialistas- linda simple y llanamente en las creencias y en el acto de fe.

\section{REFERENCIAS}

Burckhardt, J. (1945). Del Paganismo al Cristianismo, La época de Constantino el Grande (272-337 D.C.) México. Ed., FCE

Dickson, A. (1972). La lucha entre el dogmatismo y la ciencia en el seno de la cristiandad. México. Siglo XXI Editores

Durkheim, È. (1993). Sociedad y moralidad, Madrid, Alianza Editorial. 
Galicia, M. \& Orozco, G. (2013). Valoración de la semántica en la comprensión de palabras orales, Revista Chilena de Neuropsicología, 8 (2), pp. 27-30. Recuperado 16 de septiembre de 2015 desde:

file://C:/Users/Ger/Desktop/179329660001.pdf

Grossi, V. (2013). Nota sobre la semántica de la expresión “Iglesia católica”, antes y después del ‘Edicto' de Constantino del 313, Anuario de Historia de la Iglesia, 22, pp. 111-133. Recuperado 16 de septiembre de 2015 desde:

file:///C:/Users/Ger/Downloads/Nota\%20sobre\%20la\%20sem\%C3\%A1ntica\%20de\%20la\% 20expresi $\%$ C3\%B3n $\% 20 \%$ C2\%ABlglesia $\% 20$ cat $\%$ C3\%B3lica $\%$ C2 $\%$ BB $\% 20$ antes $\% 20 y \% 20$ despu $\%$ C3 $\%$ A 9s\%20del $\% 20$ 'Edicto'\%20de\%20Constanti.pdf

Hernández, Ó. (2012). La semiótica musical como herramienta para el estudio social de la música, Cuadernos de Música, Artes visuales y Artes escénicas, 7 (1), pp. 11-38. Recuperado el 12 de septiembre de 2015 desde: file:///D:/Downloads/Dialnet-LaSemioticaComoHerramientaParaEIEstudioSoci-3890435.pdf

Magaña, A. (1986). Sagrada Biblia, México, Ediciones Paulinas, XXVII

Martín, M. (2014). La música como instancia relatora. Sus aportaciones a la mímesis en la ópera decimonónica, Revista Signa, 23, pp. 611-634. Recuperado 16 de septiembre de 2015 desde: file:///C:/Users/Ger/Downloads/DialnetLaMusicaComolnstanciaRelatoraSusAportacionesALaMim4526803.pdf

Méndez, A. (2012). Mejor que el significado. El umbral simbólico entre sonido y sentido, Revista Faro ,15 pp.1-15. Recuperado el 12 de septiembre de 2015 desde:

file:///C:/Users/Ger/Downloads/Dialnet-MejorQueEISignificado-4160155\%20(1).pdf

Mora, E. \& Asuaje, R. (2011), El canto de la palabra: una iniciación al estudio de la prosodia. (pp.17-33), Venezuela: www.2.ula.ve/publicacionesacademico. Recuperado el 26 de septiembre del 2015 desde: http://www.serbi.ula.ve/serbiula/librose/pva/Libros\%20de\%20PVA\%20para\%20libro\%20digital/prosodia.pdf

Ricaurte, P. (2014). Hacia una semiótica de la memoria, En-claves del Pensamiento, 8 (16), pp.31-54. Recuperado el 12 de septiembre de 2015 desde:

http://micampus.ccm.itesm.mx/documents/10633/139829379/2.+Hacia+una+semio\%CC\%81tica+de+la+me moria.pdf/ba4779fd-585e-4f61-85ee-354ea04e5b97 
Runes. D. (1969). Diccionario de Filosofía. España. Tratados y manuales Grijalbo.

Torres, H. (2012). Semiótica y Semántica de la Notación Musical Nuevas Fronteras, El Artista, 8, pp. $287-$ 311. Recuperado el 12 de septiembre de 2015 desde:

file:///C:/Users/Ger/Downloads/DialnetSemioticaYSemanticaDeLaNotacionMusicalNuevasFronte4100160.pdf

Ussa, M. (2013). Semántica gestual y comunicación humana, Cuadernos de Lingüística Hispánica, 21, pp. 89-10. Recuperado 16 de septiembre de 2015 desde:

file://C:/Users/Ger/Downloads/Sem\%C3\%A1ntica\%20gestual\%20\%20y\%20comunicaci\%C3\%B3n \%20hum ana.pdf

Vallejo, G. (2011). La semiótica: un aporte metodológico para la comprensión de la cultura somática, Revista Educación física y deporte, 30 (1), pp. 367.334. Recuperado 16 de septiembre de 2015 desde: http://aprendeenlinea.udea.edu.co/revistas/index.php/educacionfisicaydeporte/article/view/367

Vinasco, J. (2012). Una perspectiva semiótica de la interpretación musical, Cuadernos de Música, Artes visuales y Artes escénicas, 7 (1), pp. 11-38. Recuperado el 12 de septiembre de 2015 desde: file:///C:/Users/Ger/Downloads/Dialnet-UnaPerspectivaSemioticaDeLalnterpretacionMusical$\underline{3890401 \% 20(1) . p d f}$

Tendencias21. (2011). Ontología del universo y hermenéutica cristiana (IV): la idea teológica del hombre. Monserrat, J. Recuperado el 2 de octubre del 2015 desde:

http://www.tendencias21.net/concilio/Ontologia-del-universo-y-hermeneutica-cristiana-IV-la-idea-teologicadel-hombre_a12.html

El padre nuestro en arameo. Recuperado el 19 de agosto del 2015 desde: http://www.torahweb.net/t1047-awon-d-bish-maiya-padre-nuestro-en-arameo

El padre nuestro en hebreo y arameo. Recuperado el 19 de agosto del 2015 desde: http://vivificar.blogspot.com/2009/06/el-padre-nuestro-en-hebreo-y-arameo.htm|\#ixzz3jKNQkZOF 